\title{
Median QTcF
}

National Cancer Institute

\section{Source}

National Cancer Institute. Median QT CF. NCI Thesaurus. Code C102253.

A measurement of the median duration (time) of the QT c interval, obtained from a set of measurements of the QT interval and corrected using the Fridericia's correction formula. 